\title{
POTENCIALIDADE DE UTILIZAÇÃO DA ENERGIA GEOTÉRMICA NO BRASIL - UMA REVISÃO DE LITERATURA
}

\author{
Nathana Karina Swarowski Arboit ${ }^{1}$ \\ Samara Terezinha Decezaro ${ }^{2}$ \\ Gilneia Mello do Amaral ${ }^{3}$ \\ Tiago Liberalesso ${ }^{4}$ \\ Vinicio Michael Mayer ${ }^{5}$ \\ Pedro Daniel da Cunha Kemerich ${ }^{6}$
}

\begin{abstract}
Resumo: A energia geotérmica, originada do calor proveniente do interior da Terra, é uma fonte de energia que se apresenta como solução para alguns problemas atuais de energia e do meio ambiente. Existem basicamente duas formas de aproveitamento do recurso geotérmico, para geração de eletricidade e para usos diretos. O objetivo deste trabalho é apresentar uma revisão de literatura sobre a potencialidade de aplicação da energia geotérmica no Brasil, identificando estudos de potencial geotérmico e experiências de sucesso no país. No Brasil, ainda são poucos os estudos referentes a utilização de energia geotérmica, devido principalmente a comodidade do país quanto às questões energéticas, que tem como base a hidroeletricidade. Através dessa revisão, foi possível identificar no Brasil, o potencial para utilização de recursos de alta, e principalmente, de baixa temperatura, estes últimos indicados para diversas formas de usos diretos, como residencial, industrial e na agricultura, além da recreação. A viabilidade de utilização da energia geotérmica no Brasil ainda é discutida, mas há grande expectativa quanto ao desenvolvimento de técnicas que possibilitem ampliar a utilização da energia geotérmica no país, como através da exploração do potencial geotérmico do Aquífero Guarani e a utilização de bombas de calor geotérmicas.
\end{abstract}

Palavras-chave: Energia Geotérmica; Usos Diretos; Brasil.

\section{Potential of Geothermal Energy Use in Brazil - Review}

\begin{abstract}
The geothermal energy, originated from the interior heat of the Earth is an energy source that presents a solution to current energy and environment problems. There are basically two ways to use the geothermal resource, electricity generation and direct uses. The objective of this work is to present a literature review on the application of geothermal energy in Brazil, identifying studies of geothermal potential and successful experiences in the country. In Brazil, there are few studies on the use of geothermal energy, mainly due to the convenience of the country regarding energy issues, which is based on hydroelectricity. Throughout this review, it was possible to identified in Brazil, a potential utilization of high and especially, low temperature resources, the last one suitable for several forms of direct uses such as residential, industrial and agricultural, besides recreational. The feasibility of using geothermal energy in Brazil is still debated, but there is great expectations regarding the development of techniques that will allow the expansion of the utilization of geothermal

\footnotetext{
${ }^{1}$ Acadêmica do Curso de Engenharia Ambiental da Universidade Federal de Santa Maria (UFSM). E-mail: nathanaksa@yahoo.com.br

${ }^{2}$ Acadêmica do Curso de Engenharia Ambiental da Universidade Federal de Santa Maria (UFSM). E-mail: samaradecezaro@hotmail.com

${ }^{3}$ Acadêmica do Curso de Engenharia Ambiental da Universidade Federal de Santa Maria (UFSM). E-mail: gil.a@hotmail.com

${ }^{4}$ Acadêmico do Curso de Engenharia Ambiental da Universidade Federal de Santa Maria (UFSM). E-mail: thiagoliberalesso@hotmail.com

${ }^{5}$ Acadêmico do Curso de Engenharia Ambiental da Universidade Federal de Santa Maria (UFSM). E-mail: vinimayer@hotmail.com

${ }^{6}$ Professor Assistente da Universidade Federal de Santa Maria (UFSM). E-mail: eng.kemerich@yahoo.com.br DOI: 10.7154/RDG.2013.0026.0008
} 
energy in the country, like through the exploration of the geothermal potential of the Guarani Aquifer and the use of Geothermal Heat Pumps.

Keywords: Geothermal Energy; Direct Uses; Brazil.

\section{INTRODUÇÃO}

Com a possível escassez de combustíveis fósseis e as preocupações crescentes sobre os problemas ambientais que os mesmos causam, o uso de recursos energéticos renováveis tende a aumentar e diversificar. A energia geotérmica, definida como a energia térmica proveniente do interior da Terra, pode ser capaz de solucionar alguns desses problemas atuais de energia e do meio ambiente, se tornando um recurso fundamental para tornar a sociedade mais sustentável (OZGENER; HEPBASLI; DINCER, 2007).

No seu processo de arrefecimento, o calor do interior da Terra pode ser dissipado em qualquer ponto da superfície terrestre (BICUDO, 2010). Porém, de acordo com o autor, existem regiões onde a libertação deste calor é mais intensa, normalmente coincidente com zonas ativas das fronteiras das placas tectônicas do globo.

No Brasil, ainda são poucos os estudos referentes a utilização do recurso geotérmico. No entanto, segundo Lund, Freeston e Boyd (2011), muitos países vêm realizando estudos do potencial de utilização de energia geotérmica, os quais estão demonstrando que esta já pode ser desenvolvida praticamente em qualquer lugar, pois em países em que não existe atividade vulcânica, recursos geotérmicos de temperatura baixa ou moderada também podem ser executados através de uso direto, os quais estão demonstrando boa eficiência.

Os recursos geotermais podem ser classificados como sendo de baixa entalpia, média e alta entalpia (SOUZA FILHO, 2012). Singhal e Gupta (2010) classificam em três grupos os sistemas geotermais: (i) Baixa entalpia ou sistemas por domínio de água quente - com temperaturas que variam de 50 a $150^{\circ} \mathrm{C}$, em que a água subterrânea, quente, é utilizada como fonte de calor; (ii) Alta entalpia ou sistema por domínio de vapor - com temperaturas na faixa de 150 a 300 ㄷ, em que o vapor é extraído do líquido, que é utilizado para mover turbinas de geração de eletricidade; (iii) Sistemas de rochas secas e quentes (hot dry rock - HDR) - com temperaturas entre 50 e $300^{\circ} \mathrm{C}$, em que a água é circulada para níveis mais profundos em fraturas criadas artificialmente ou não, onde é aquecida, desse modo a água quente e o vapor movem-se para a superfície para serem utilizados como fontes de energia geotermal. 
Entretanto, o aproveitamento das fontes geotermais está condicionado à verificação da coexistência das seguintes condições, que configuram um reservatório geotérmico: (i) a existência de uma fonte de calor, a qual poderá ser um corpo magmático ou rochas quentes; (ii) um fluido transportador de calor, como a água, dispondo de adequada recarga face à extração; (iii) uma sequência de rochas permeáveis, que constitui o reservatório e (iv) uma formação geológica não permeável e isolante de cobertura, resultante da atividade hidrotermal do geofluido, que concentra e retém toda a energia contida no reservatório (BICUDO, 2010).

Para Rabelo et al. (2002), a temperatura ideal para uso direto da energia térmica se encontra entre $35^{\circ} \mathrm{C}$ e $148^{\circ} \mathrm{C}$, com aplicação residencial, na agricultura e na indústria, já em se tratando de produção de eletricidade, os autores relatam que as temperaturas devem girar em torno de $300^{\circ} \mathrm{C}$ ou mais.

Lund, Freeston e Boyd (2011) referindo-se aos usos diretos, em estudos de aproveitamento da energia geotérmica a nível mundial destacam diversas categorias de utilização, entre as principais estão: aquecimento de ambientes, usos industriais, bombas de calor geotérmicas, banho e natação, refrigeração, derretimento de neve, aquecimento de lagoas de aquicultura e aquecimento de estufas.

Segundo Vichi e Mansor (2009), a energia geotérmica pode ser economicamente viável, e pode fazer uma significativa contribuição para um país ou região mix de energia, como é o caso do Brasil, que tem grande parte de sua matriz energética baseada em fontes renováveis. Segundo os mesmos autores, o crescimento econômico recente tem ampliado a participação das fontes não renováveis na matriz energética brasileira, em razão disso, como forma de compensar os impactos causados por esse aumento, deverá ocorrer também a ampliação do uso de fontes renováveis já consolidadas, como as pequenas centrais hidrelétricas ( $\mathrm{PCH})$, os biocombustíveis, e as energias solar e eólica, além do investimento em pesquisa e desenvolvimento de fontes renováveis ainda não consolidadas, como é o caso da energia geotérmica.

Diante do exposto, o objetivo deste trabalho é apresentar uma revisão de literatura sobre a potencialidade de aplicação da energia geotérmica no Brasil, identificando estudos de potencial geotérmico e experiências de sucesso no país. 


\section{Energia Geotérmica no Brasil}

No contexto mundial, o incentivo, o desenvolvimento de tecnologias e o aproveitamento do recurso geotermal se dão essencialmente nos países desenvolvidos, uma vez que nestes as fontes fósseis não podem mais assegurar sozinhas o desenvolvimento socioeconômico em consonância com a preservação do meio ambiente (CASTRO et al., 2009).

Conforme Gomes (2009), no final de 2008, 25 países estavam produzindo eletricidade proveniente de recursos geotermais, com uma capacidade total instalada de 10.469,7 MW, sendo que os Estados Unidos tinham em desenvolvimento 86 projetos geotérmicos, pretendendo até o ano de 2015 gerar $6.300 \mathrm{MW}$ com uso de energia geotermal, suficiente para fornecer energia para seis milhões de residências.

No Brasil, a situação já não é a mesma, tendo em vista dois motivos principais. Primeiro, o país apresenta sua matriz energética assentada em bases hídricas, além da disponibilidade de outras fontes de energia, como por exemplo, o gás natural (CASTRO et al., 2009). Essa realidade, de certa forma, relega a um segundo plano a necessidade de se desenvolver e promover outras fontes de energia. Segundo, porque a ausência de atividades tectonomagmáticas em tempos geológicos considerados relativamente recentes implica que o regime térmico da grande parte da crosta da plataforma Sul Americana seja considerado estacionário, e assim, condições desta natureza são favoráveis para a ocorrência de recursos geotermais de baixa entalpia, sendo por este motivo que no Brasil o aproveitamento está voltado mais para fins recreativos e de lazer (GOMES, 2009).

Deve se levar em consideração que, segundo a ANEEL (2008), a evolução da utilização da geotermia para geração de energia elétrica a nível mundial foi lenta e se caracterizou pela construção de pequeno número de unidades em poucos países, sendo que no Brasil não se tem conhecimento sobre a existência de usinas em operação, nem sob a forma experimental.

Contudo, segundo Hamza et al. (2010), foi identificado no Brasil o potencial para sistemas de alta temperatura geotérmica, embora esse potencial pareça estar restrito às ilhas atlânticas de Fernando de Noronha e Trindade. Por outro lado, segundo os autores, recursos de baixa temperatura $\left(<90^{\circ} \mathrm{C}\right)$ foram identificados no Brasil em número significativo, sendo que a maior parte dos recursos geotérmicos está localizada no centro-oeste do Brasil (nos estados de Goiás e Mato Grosso) e no sul (no estado de Santa Catarina). Os autores também relatam que o potencial para a exploração em grande escala de água de baixa temperatura 
geotérmica para utilização industrial e aquecimento de espaços é considerada significativa na parte central da bacia Paraná (situada nas regiões Sul e Sudeste do Brasil). Conforme Hamza, Gomes e Ferreira (2005) no município de Cornélio Procópio, no estado do Paraná, tem-se registro de uma indústria que se utiliza, desde de 1980, de dois poços, onde a água geotérmica bombeada a 50 드, é utilizada no pré aquecimento das caldeiras para produção de café em pó. De maneira semelhante, em Taubaté, no interior de São Paulo, a água geotermal, com temperatura de $48 \stackrel{\circ}{ }$ C, foi utilizada durante as décadas de 1970 a 1980 no processamento industrial da madeira.

De acordo com Cardoso, Hamza e Alfaro (2010), os recursos geotérmicos explorados no Brasil são estimados em $250 \mathrm{MWt}$ (Mega Watt termal), sendo que o país apresenta uma localidade considerada de alta entalpia e 25 localidades consideradas de baixa entalpia. A figura 1, resultado dos estudos de Hamza et al. (2008), apresenta o fluxo de calor para a América do Sul. Observa-se que, para o Brasil, os maiores valores (entre $80-100 \mathrm{~mW} / \mathrm{m}^{2}$ ) se encontram nas regiões Sudeste, Centro-Oeste, Nordeste e Sul.

O Instituto Brasileiro de Geografia e Estatística - IBGE publicou em 2010 o Atlas Nacional do Brasil, onde estão disponíveis uma série de mapas geotermais, como os de recurso base e recurso recuperável, os quais são mostrados nas figuras 2 e 3.

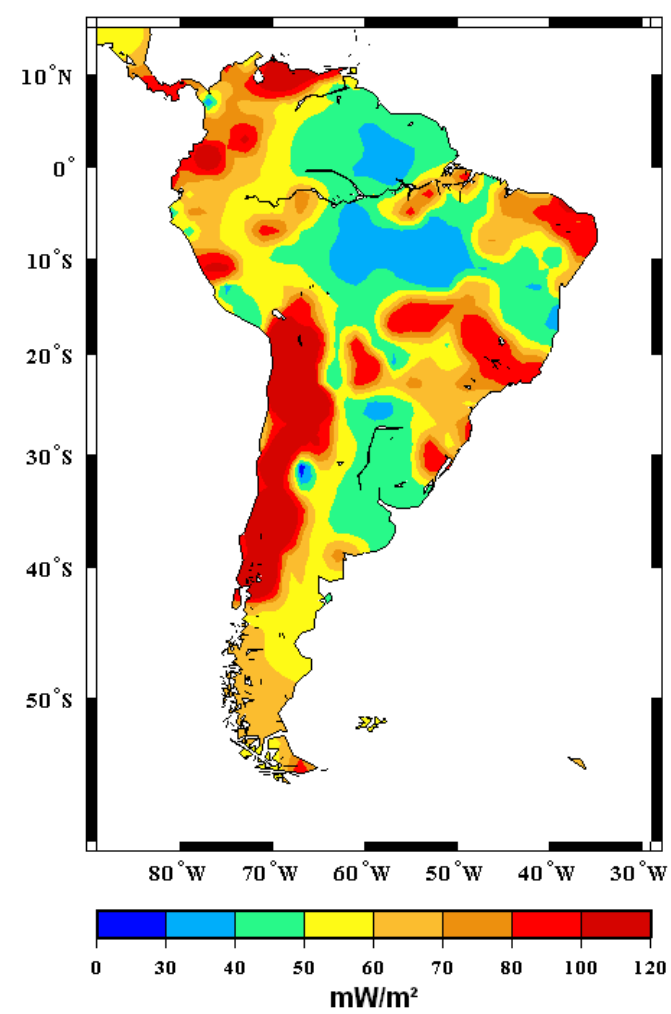

Figura 1- Mapa de fluxo de calor geotérmico para a América do Sul Fonte: Hamza et al. (2008) 


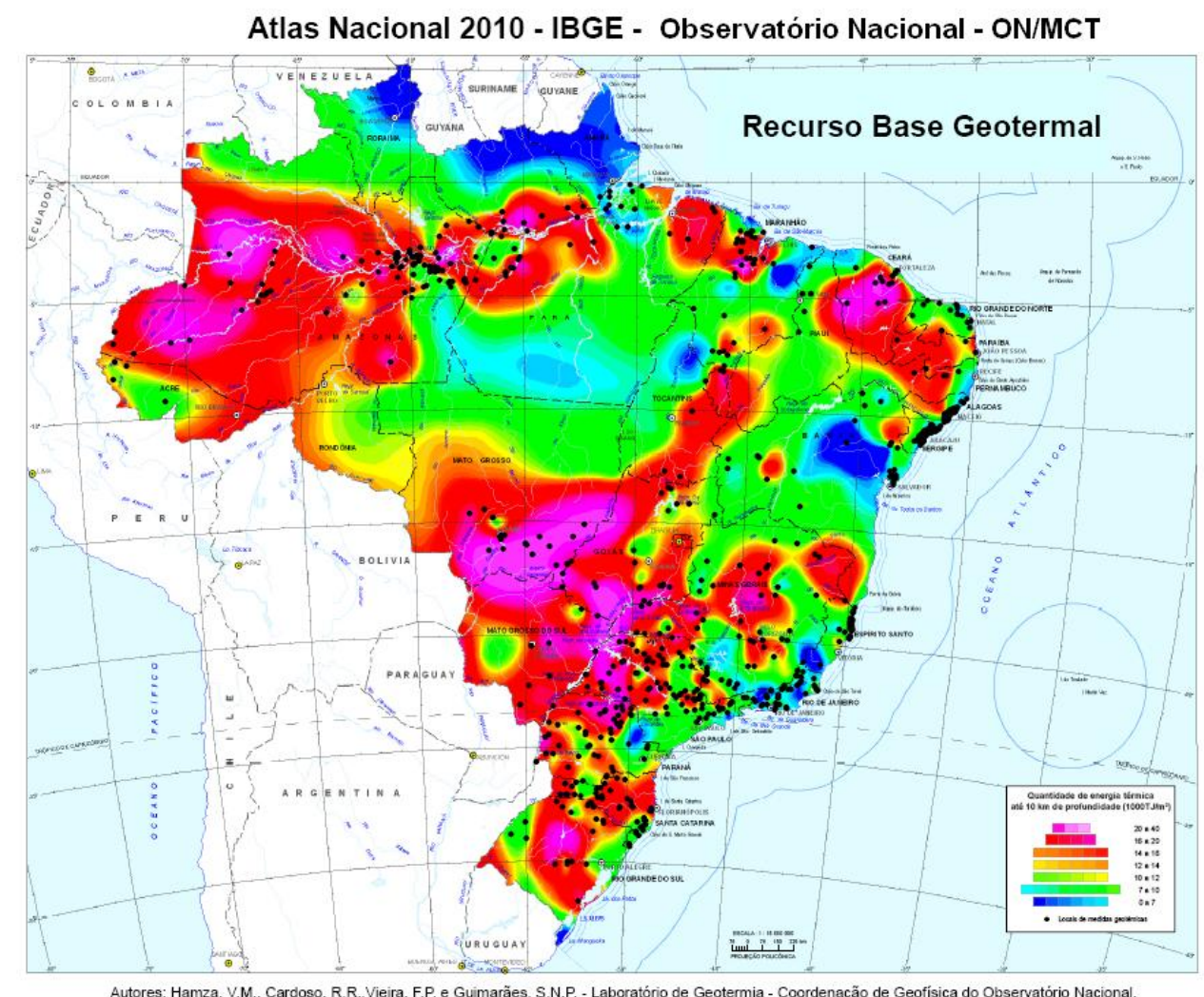

Figura 2 - Mapa de Recurso Base Geotermal para o Brasil

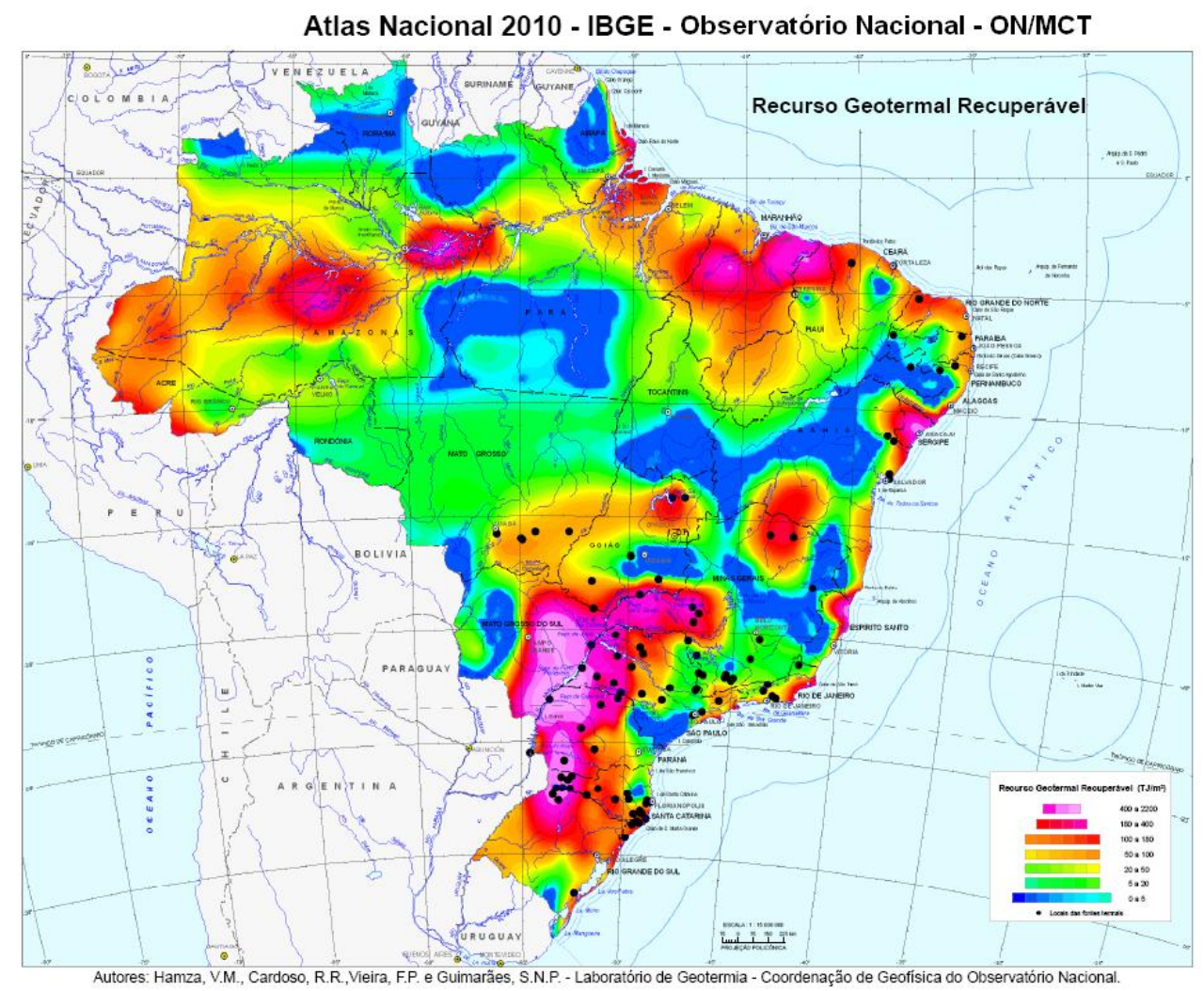

Figura 3 - Mapa de Recurso Geotermal Recuperável 
Há também indícios que apontam para a ocorrência de recursos geotérmicos de temperatura média em profundidades de 3 a $5 \mathrm{Km}$ nas regiões nordeste e central do Brasil e existência de recursos de baixa temperatura no sistema Aquífero Guarani (CARDOSO; HAMZA; ALFARO, 2010).

No entanto, atualmente, a energia geotérmica no Brasil é usada quase que unicamente para fins de recreação, em parques de fontes termais, como Caldas Novas (GO), Piratuba (SC), Araxá (MG), Olímpia, Águas de Lindóia e Águas de São Pedro (SP) (VICHI; MANSOR, 2009).

\section{Estudos de Potencial Geotérmico no Brasil}

Conforme Hamza, Gomes e Ferreira (2005), as investigações sistemáticas dos recursos geotérmicos no Brasil começaram na década de 1970 e desde então, uma quantidade bastante significativa de informações tem sido adquirida.

De acordo com Gomes (2009) os primeiros estudos de avaliação de recursos geotermais no Brasil foram realizados pelos trabalhos de Hamza e Eston (1981) e Hamza (1983). Mais recentemente, estudos em escala regional têm abordado a avaliação e o aproveitamento do recurso geotermal tanto para uso direto, como para geração de eletricidade. Referente a isso, entre os poucos estudos desenvolvidos, destacam-se os trabalhos efetuados por Alexandrino, Couy e Rodrigues (2012), Gomes e Hamza (2005), Gomes (2009), Souza Filho (2012) e Rabelo et al. (2002), os quais são descritos a seguir.

Alexandrino, Couy e Rodrigues (2012) avaliaram o potencial geotérmico no estado de Minas Gerais, através de estudos que demonstrassem a temperatura à profundidades de 3 e $5 \mathrm{Km}$. Os resultados indicam que as regiões de maior excesso de temperatura são a Bacia do São Francisco, o Triângulo Mineiro, e pequenos trechos na região Sul e Sudeste do estado que apontam temperaturas entre $150^{\circ} \mathrm{C}$ e $180^{\circ} \mathrm{C}$, classificados como recursos térmicos de alta entalpia.

Gomes (2009) através de dados geotérmicos e estudos geológicos e geofísicos pôde determinar o fluxo geotérmico e o seu mapeamento na Bacia do Paraná. O autor constatou, de modo geral, que a Bacia é caracterizada por recursos geotérmicos do tipo de baixa entalpia. Assim, no que se refere ao aproveitamento de recursos geotermais destacam-se as possibilidades de utilização para fins balneológicos e turismo termal. 
Souza Filho (2012) avaliou e estudou a exploração geotermal para geração de energia elétrica, através da injeção de fluidos circulantes no meio fraturado de rochas sedimentares na Bacia de Taubaté que ao serem aquecidos, retornam à superfície em forma de vapor, para então serem aproveitados. Em síntese, o autor chegou a conclusão de que duas áreas no vale do Paraíba despertaram interesse e serão objeto de novas prospecções.

Gomes e Hamza (2005) divulgaram os resultados de estudos geotérmicos efetuados em 72 localidades na avaliação de gradientes de temperatura e o fluxo geotérmico da crosta superior no Estado do Rio de Janeiro, os autores afirmam que de acordo com as estatísticas atuais, o Rio de Janeiro se destaca como o estado brasileiro com a maior densidade de dados para medições de energia geotérmica no Brasil.

Já Rabelo et al. (2002), estudaram a potencialidade de aproveitamento da energia geotérmica proveniente da área de abrangência do Aquífero Guarani, encontrado nos estados de Goiás, Mato Grosso do Sul, Minas Gerais, São Paulo, Paraná, Santa Catarina e Rio Grande do Sul. Segundo os autores, no Brasil, o aproveitamento de reservatórios geotérmicos do Aquífero Guarani restringe-se ao uso direto em aplicações agrícolas e industriais, mas apesar das baixas temperaturas (máx. $70 \circ \mathrm{C}$ ), estima-se uma reserva explorável de energia geotérmica equivalente a 50 bilhões de toneladas de petróleo.

\section{Tendências para Utilização de Energia Geotérmica no Brasil}

A viabilidade de utilização da energia geotérmica no Brasil ainda é discutida, sendo necessários estudos que revelem, de forma mais aprofundada, a real potencialidade de aplicação desse tipo de energia no Brasil.

Segundo Alves (2007), atualmente estão em pauta investimentos principalmente quanto à exploração do potencial geotérmico do Aquífero Guarani, cuja temperatura da água, inclusive pode ser capaz de aquecer a água de edifícios ou casas e sistemas de calefação e lareiras. Ainda, segundo Alves (2007), a expectativa para os próximos anos é que a utilização de bombas de calor se torne comum em condomínios brasileiros.

\section{Aquífero Guarani}

O Sistema Aquífero Guarani está situado na porção Centro-Leste do continente sulamericano, distribuído por uma área de cerca de $1.196 .500 \mathrm{~km}^{2}$, fazendo parte do território 
de quatro países, Argentina, Paraguai, Uruguai e Brasil, sendo que neste último o aqüífero se distribui por uma área em torno de $840.800 \mathrm{~km}^{2}$, ao longo de oito Estados da Federação: Mato Grosso do Sul, Rio Grande do Sul, São Paulo, Paraná, Goiás, Minas Gerais, Santa Catarina e Mato Grosso (RIBEIRO, 2008). Segundo o autor, o Brasil está em uma posição estratégica, pois além de conter a maior parte das reservas subterrâneas, também conta com muitas áreas de recarga.

De acordo com Rabelo et al. (2002), devido ao fato de o Sistema Aquífero Guarani, conter reservatórios geotérmicos de baixa temperatura e com baixos gradientes térmicos, não existe a possibilidade de aproveitamento do mesmo para produção de energia elétrica, contudo, é conhecido o potencial para uso direto da água aquecida, que apresenta grande possibilidade de exploração, devido ao fato de existirem atividades diversificadas na área de abrangência, tanto agrícolas como industriais. Os autores citam 4 conjuntos de atividades efetivamente aplicáveis para aproveitamento do potencial geotérmico desse aqüífero, sendo elas: (i) como fonte de abastecimento público; (ii) como meio para desenvolver as atividades agroindustriais que utilizam água normalmente entre 37 e $75{ }^{\circ} \mathrm{C}$, especialmente aquelas destinadas à lavagem de couro de animais, secagem de grãos, pasteurizações e climatização de criatório de animais; (iii) como integrante de processos industriais que exijam préaquecimento e (iv) como meio de desenvolver o turismo, facilitando a instalação de estâncias e parques hidrotermais.

Segundo Rodrigues e Arruda (2006), o potencial térmico do Aquífero Guarani como fonte alternativa de energia tem sido pouco explorado, principalmente no contexto do turismo, sendo que atualmente o aproveitamento desse sistema está voltado principalmente para o consumo humano e industrial. Os autores destacam o potencial do hidrotermalismo como fonte de energia não convencional, que pode contribuir para o aproveitamento sustentável do Aquífero Guarani.

\section{Bombas de calor geotérmicas}

Conforme descrito anteriormente, o Brasil apresenta fontes geotérmicas de baixa entalpia, sendo assim, o recurso presta-se para usos diretos, como aquecimento doméstico. Essa aplicação é possível através de bombas de calor ou Ground-Source Heat Pump - GSHP. Uma bomba de calor é um dispositivo que extrai calor de um local (a fonte de calor) e o torna disponível para outro local (o dissipador de calor), utilizando um sistema mecanizado. 
Isso pode ser feito de modo a arrefecer uma área, através da remoção de calor da mesma, e também aquecer uma área através da liberação de calor para a unidade (LIVINGSTONE, 2010).

Segundo Tavares (2011), GSHP são equipamentos que aproveitam e transferem o calor, armazenado a poucos metros abaixo da superfície terrestre, possibilitando sua utilização para aquecimento de água e de edificações. Segundo o mesmo autor, nas estações frias, esses sistemas funcionam a partir da recuperação, através de tubos subterrâneos, do calor armazenado em subsuperfície, sendo que nas estações quentes esse processo é invertido, de modo que o calor da habitação é transferido e dissipado no subsolo.

Conforme ilustra a figura 2, um sistema GSHP tem três componentes principais, sendo: a bomba de calor propriamente dita (1), uma conexão com a terra (2) e um sistema interior de aquecimento ou resfriamento (3) (MINISTER OF NATURAL RESOURCES CANADA, 2005; ACEP e CCHRC, 2008).

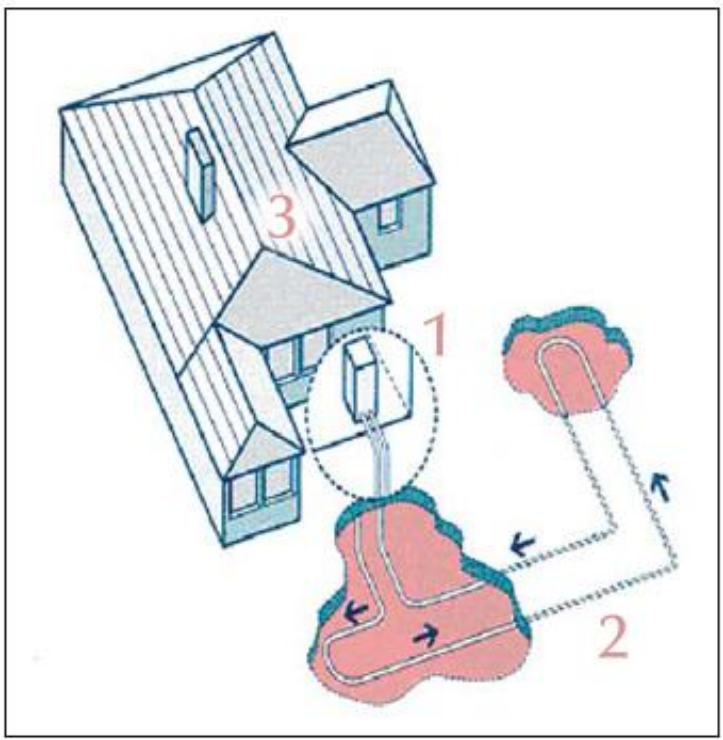

Figura 4- Três principais componentes de um sistema GSHP Fonte: Minister of Natural Resources Canada (2005).

A vantagem de bombear o calor é que, quando isso é feito, uma quantidade menor de energia elétrica é utilizada, se comparada à necessária para converter energia elétrica em calor utilizando fornalhas e aquecedores elétricos ou em calefatores radiantes convencionais e, além disso, pelo aspecto ambiental, deve-se considerar o grande impacto na redução de emissões de $\mathrm{CO}_{2}$ (LOBO et al., 2004).

Esta tecnologia apresenta-se ainda incipiente no Brasil, mas desponta como uma alternativa energética bastante promissora. Há de se considerar que o potencial para exploração em 
larga escala de águas de baixa temperatura geotérmica, tanto para utilização industrial quanto para aquecimento de espaços é considerado significativo na parte central da bacia do Paraná (situada no sul e sudeste do Brasil), sob condições de clima subtropical (HAMZA et al., 2010).

\section{CONCLUSÕES}

O calor proveniente do interior da terra é uma fonte de energia limpa que está disponível em várias regiões do planeta, podendo ser utilizada para gerar eletricidade e para diversos usos diretos. Se obtivermos tecnologias sólidas e viáveis para a exploração e aproveitamento da energia geotérmica será possível alcançar uma revolução energética e reduzir de maneira significativa a dependência do homem por combustíveis fósseis.

No mundo, um número considerável de países está produzindo energia elétrica a partir do recurso geotérmico. No Brasil, a realidade não é a mesma, tendo em vista que os poucos estudos desenvolvidos apontam, predominantemente, a existência de baixas temperaturas em subsuperfície e, portanto, o aproveitamento se restringe para usos diretos, o que atualmente se dá principalmente para fins de lazer e recreação, com poucos relatos de usos industriais, como nos casos de Cornélio Procópio e Taubaté. Apenas algumas regiões no estado de Minas Gerais e as ilhas de Fernando de Noronha e Trindade parecem ter temperaturas subsuperficiais caracterizadas como de alta temperatura.

Muito embora, até o momento, no Brasil, não haja estudos experimentais que visem a exploração da energia geotérmica para fins de eletricidade, a utilização da energia geotérmica para usos diretos se mostra bastante promissora, destacando-se o aproveitamento da água do Aquífero Guarani para atividades agroindustriais, como integrante de processos industriais e como meio de desenvolver o turismo e também a utilização de bombas de calor geotérmicas, tanto para utilização industrial quanto para aquecimento de espaços.

\section{REFERÊNCIAS}

ALEXANDRINO, C. H.; COUY, C. E. M.; RODRIGUES, F. L. Avaliação dos recursos geotérmicos de Minas Gerais. Revista Vozes dos Vales , n.1, ano I, 2012. Disponível em: < http://www.ufvjm.edu.br/site/revistamultidisciplinar/files/2011/09/Avalia\%C3\%A7\%C3\%A3 o-dos-recursos-geot\%C3\%A9rmicos-deMinas-Gerais.pdf>. Acesso em: 2 abril 2013. 
ALVES, J. T. Energia sob nossos pés. Revista Arquitetura e Construção, 2007. Disponível em: <http://planetasustentavel.abril.com.br/noticia/energia/conteudo_231671.shtml>. Acesso em: 31 dez. 2012.

ANEEL - AGÊNCIA NACIONAL DE ENERGIA ELÉTRICA. Atlas de energia elétrica do Brasil. 3 ed. Brasília, 2008.

BICUDO, C. Energia Geotérmica. Sentir e Interpretar os Açores (SIARAM). 2010. Disponível em: < http: //siaram.azores.gov.pt/energia-recursos-hidricos/geotermia/energiageotermica.pdf>. Acesso em: 05 jan. 2013.

CARDOSO, R. R.; HAMZA, V. M.; ALFARO, C. Geothermal Resource Base for South America: A Continental Perspective. In: PROCEEDINGS WORLD GEOTHERMAL CONGRESS, 2010. Bali, Indonesia, 2010. Disponível em: < http://www.geothermalenergy.org/pdf/IGAstandard/WGC/2010/1618.pdf>. Acesso em: 2 abril. 2013.

CASTRO, N. J. de, et al. A importância das fontes alternativas e renováveis na evolução da matriz energética brasileira. In: V SEMINÁRIO DE GERAÇÃO E DESENVOLVIMENTO SUSTENTÁVEL. 25 de ago. de 2009. Disponível em: < http://www.nuca.ie.ufrj.br/gesel/artigos/GESEL_-_Estudo_Mapfre__260809[1].pdf>. Acesso em: 20 mar. 2013.

GOMES, A. J. L. Avaliação de recursos geotermais da Bacia do Paraná. Tese (Doutorado em Geofísica) - Observatório Nacional. Rio de Janeiro, 2009.

GOMES, A. J. L. Avaliação dos recursos geotermais no estado do Rio de Janeiro. Dissertação (Mestrado em Geofísica)- Observatório Nacional do Rio de Janeiro, 2003.

GOMES, A. J. L.; HAMZA, V. M. Geothermal gradient and heat flow in the state of Rio de Janeiro. Revista Brasileira de Geofísica. 325-347 p. 2005. Disponível em: < http://www.scielo.br/pdf/rbg/v23n4/a01v23n4.pdf>. Acesso em: 20 mar. 2013.

HAMZA, V. M.; GOMES, A. J. L.; FERREIRA, L. E. T. Status Report on Geothermal Energy Developments in Brazil. In: PROCEEDINGS WORLD GEOTHERMAL CONGRESS 2005. Antalya, Turkey, 24-29 de abril, 2005. Disponível em: < http://www.geothermalenergy.org/pdf/IGAstandard/WGC/2005/0149.pdf>. Acesso em: 20 mar. 2013.

HAMZA, V. M; CARDOSO, R. R.; PONTE NETO, C. F. Spherical harmonic analysis of earth's conductive heat flow. International Journal of Earth Sciences, 2008. Disponível em: < http://link.springer.com/article/10.1007\%2Fs00531-007-0254-3\#page-1>. Acesso em: 15 mar. 2013.

HAMZA, V. M., CARDOSO, R. R., GOMES, A. J. L., ALEXANDRINO, C.H. Brazil: country update. In: PROCEEDINGS OF THE 2010 WORLD GEOTHERMAL CONGRESS, Bali, Indonesia, 25-29 de abril, 2010, paper $n^{\circ} 0147$.

INSTITUTO BRASILEIRO DE GEOGRAFIA E ESTATÍSTICA-IBGE. Atlas Nacional do Brasil Milton Santos, 2010.2 Disponível em: <.ftp://geoftp.ibge.gov.br/atlas/atlas_nacional_do_brasil_2010/>. Acesso em: 25 jun. 2013. 
LIVINGSTONE, P. M. An Investigation into the Suitability of Air and Ground Source Heat Pumps to the UK environment with a Swimming Pool Complex Heat Pump Installation. Thesis (Masters Course of Science in Renewable Energy Systems and the Environment). Department of Mechanical Engineering - University of Strathclyde. 2010.

LUND, J. W.; FREESTONB, D. H.; BOYDA, T. L. Direct utilization of geothermal energy 2010 worldwide review. Geothermics. p. 159-180, 2011. Disponível em: < http://www.sciencedirect.com/science/article/pii/S0375650511000344>. Acesso em: 15 mar. 2013.

LOBO, J. W.; AOKI, A. R.; TEIXEIRA, M. D; PAULILLO, G. Determinação da eficiência e da aplicabilidade de bombas de calor em clima temperado subtropical-típico da região Sul do país - Primeira fase. Revista Espaço Energia. ed. 01. Outubro, 2004. Disponível em: http://www.espacoenergia.com.br/edicoes/1/001-04.pdf>. Acesso em: 10 mar. 2013.

MINISTER OF NATURAL RESOURCES CANADA. Ground- Source Heat Pump: Project Analysis. Canadá, 2005.

OZGENER, L.; HEPBASLI, A.; DINCER, I. Parametric study of the effect of dead state on energy and exergy efficiencies of geothermal district heating systems. Heat Transfer Engineering. $2007 . \quad$ Disponível em: <http://www.ingentaconnect.com/content/tandf/uhte/2007/00000028/00000004/art00010 >. Acesso em: 5 mar. 2013.

RABELO, J. L; OLIVEIRA, J. N. de; REZENDE, R. J. de; WENDLAND, E. Aproveitamento da energia geotérmica do sistema Aqüífero Guarani: estudo de caso. In: XII CONGRESSO BRASILEIRO DE ÁGUAS SUBTERRÂNEAS. Florianópolis, 2002. Disponível em: < aguassubterraneas.abas.org/asubterraneas/article/download/.../14417>. Acesso em: 10 mar. 2013.

RIBEIRO, W. C. Aqüífero Guarani: gestão compartilhada e soberania. Estudos Avançados [online]. 2008, vol.22, n.64, pp. 227-238. ISSN 0103-4014. Disponível em: <http://www.scielo.br/scielo.php?pid=S0103-40142008000300014\&script=sci_arttext>. Acesso em: 15 mar. 2013.

RODRIGUES, A. M.; ARRUDA, L. B. Uso do hidrotermalismo do Aquífero Guarani como alternativa energética para pré-aquecimento de água. In: XIV CONGRESSO DE ÁGUAS SUBTERRÂNEAS, $2006 . \quad$ Disponível em: <aguassubterraneas.abas.org/asubterraneas/article/download/.../15269>. Acesso em: 10 mar. 2013.

SINGHAL, S. B. B.; GUPTA, P. R. Applied Hydrogeology of Fractured Rocks. 2 ed. New York: Springer Dordrecht Heidelberg, 2010.

SOUZA FILHO, M. N. Avaliação do potencial geotérmico da Bacia Sedimentar de Taubaté. Dissertação (Mestrado em Geociências)- Universidade Estadual de Campinas. Campinas, 2012.

TAVARES, J. C. Integração de Sistemas de Bombas de Calor Geotérmicas em edifícios. Dissertação (Mestrado em Engenharia Mecânica)- Universidade de Coimbra. Coimbra, 2011. 
VICHI, F. M.; MANSOR, M. T. C. Energia, meio ambiente e economia: o Brasil no contexto mundial. Química Nova. v. 32, n.3, p.757-767, 2009. Disponível em: <http://www.scielo.br/pdf/qn/v32n3/a19v32n3.pdf>. Acesso em: 4 mar. 2013.

Artigo recebido em 22/04/2013.

Artigo aceito em 02/06/2013. 